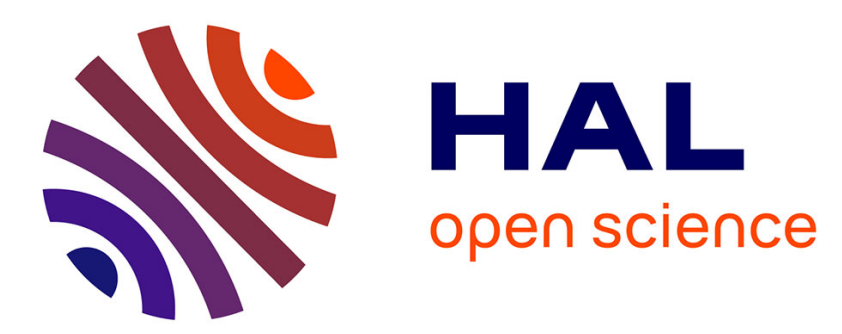

\title{
Contribution of statistical methods to the study of worn paint coatings surface topography
}

Denis Najjar, Maxence Bigerelle, François Hennebelle, Alain Iost

\section{To cite this version:}

Denis Najjar, Maxence Bigerelle, François Hennebelle, Alain Iost. Contribution of statistical methods to the study of worn paint coatings surface topography. Surface and Coatings Technology, 2006, 200 (20-21), pp.6088-6100. 10.1016/j.surfcoat.2005.09.025 . hal-01315214

\author{
HAL Id: hal-01315214 \\ https://hal.science/hal-01315214
}

Submitted on 12 May 2016

HAL is a multi-disciplinary open access archive for the deposit and dissemination of scientific research documents, whether they are published or not. The documents may come from teaching and research institutions in France or abroad, or from public or private research centers.
L'archive ouverte pluridisciplinaire HAL, est destinée au dépôt et à la diffusion de documents scientifiques de niveau recherche, publiés ou non, émanant des établissements d'enseignement et de recherche français ou étrangers, des laboratoires publics ou privés. 


\title{
Contribution of statistical methods to the study of worn paint coatings surface topography
}

\author{
D. Najjar ${ }^{\mathrm{a}, *}$, M. Bigerelle ${ }^{\mathrm{a}, \mathrm{b}}, \mathrm{F}$. Hennebelle ${ }^{\mathrm{a}}$, A. Iost $^{\mathrm{a}}$ \\ ${ }^{\text {a }}$ Laboratoire de Métallurgie Physique et Génie des Matériaux - CNRS UMR 8517, Equipe Surfaces et Interfaces, ENSAM, 8 Boulevard Louis XIV, \\ 59046 Lille cedex, France \\ ${ }^{\mathrm{b}}$ Laboratoire Roberval, FRE 2833, UTC/CNRS, Centre de Recherches de Royallieu, BP20529, 60205 Compiègne France
}

\begin{abstract}
A surface morphology can be described by numerous roughness parameters. Making the most of the power of modern computers, the relative relevance of a hundred surface roughness parameters is assessed in this investigation with regard to the relationships between the morphological texture, the low wear damage and the gloss of polymer coatings. The relevance of each roughness parameter is quantitatively determined by statistical indexes of performance defined and calculated by combining the two-way ANalysis Of VAriance (ANOVA) and the Computer Based Bootstrap Method (CBBM). The fractal dimension is shown to be the most relevant parameter for characterising the different morphological textures of studied coatings and the average curvature radius of peaks for characterising the effect of wear. A linear relationship is found between the reduction of gloss and the reduction of the average curvature radius of peaks due to wear. Besides, it is also shown that angles of $85^{\circ}$ and $20^{\circ}$ are the most relevant for characterising, respectively, the effects of the morphological texture of polymer coatings and wear on the gloss measurements.
\end{abstract}

Keywords: Paint coatings; Wear; Gloss; Statistical methods; Roughness parameters; Fractal dimension; Average curvature radius of peaks

\section{Introduction}

The precise roughness characterisation of surfaces is a major concern in many industries because of its considerable influence on its functional characteristics or properties. As far as coatings are concerned, the surface roughness of the substrate may affect for example the microstructure [1-3], the stress distribution [4] and the mechanical behaviour like adhesion strength or brittleness of the deposited coating [1,5-8]. In the same way, the surface roughness of the deposited coating may have an influence on its tribological [9-11] or optical properties [12-14].

In routine production environment, it is common to quantify surface morphology using roughness parameters such as the arithmetic average roughness $R_{\mathrm{a}}$, the root-mean square roughness $R_{\mathrm{q}}$, the peak-to valley roughness $R_{\mathrm{t}}$ or the number of peaks

\footnotetext{
* Corresponding author. Tel.: +33 3206227 65; fax: +33 320622957 .

E-mail address: denis.najjar@lille.ensam.fr (D. Najjar).
}

$N_{\mathrm{p}}$. If such conventional roughness parameters are usually estimated to qualify the surface aspect of manufactured products, it must be outlined that a surface morphology can be characterised by many other roughness parameters. Deciding without preconceived opinion which of these various parameters is the most relevant for describing the correlation between a surface morphology and a particular functional property is a difficult task of paramount importance. The relevance of each parameter is usually assessed from the conclusions of statistical tests based on inference assumptions. Because of the inflation of the roughness parameter number termed by Whitehouse the "parameter rash" [15], the proportional number of traditional statistical tests that have to be performed becomes tedious and the risk of violating the inferred assumptions (i.e. the risk of asserting wrong conclusions) increases. We have already shown that the Computer Based Bootstrap Method can be an alternative and powerful statistical tool to assess quantitatively and automatically the relative relevance of a hundred roughness parameters with regard to a linear correlation with a physical property [16-18]. 
In the case of organic paints manufactured for automotive, building trade and domestic appliance products, scratching is likely to modify their surface topography and to reduce their gloss during their lifetime [19-22]. Two major physical factors may have an effect on the magnitude of scratching: the stress level and the structure of the polymer coating under consideration. Then, for polymer coatings, we might wonder:

- which roughness parameter is the most relevant to characterise the morphology of a worn surface with regard to the stress level,

- which roughness parameter is the most relevant with regard to the structure of the coating,

- if these roughness parameters depend on each other or not.

The main purpose of this investigation is to answer the aforementioned questions without any preconceived opinion on the choice of any surface roughness parameter. Combining the two-way analysis of variance (ANOVA) and the Computer Based Bootstrap Method (CBBM), statistical indexes of performance are defined and calculated to assess quantitatively the relevance of each roughness parameter with regard to relationships between the morphological texture, the low wear damage and the gloss of different paint coatings used to protect metallic substrates against corrosive environment in building trade applications.

\section{Materials and experimental procedure}

\subsection{Polymer coatings}

For the automotive industry, building trade and domestic appliance products, paint coating is an economic way widely used to protect metallic substrates against aggressive and corrosive environments while giving them an aesthetic appearance. An organic paint coating is a complex system consisting of binders, pigments, extenders, thinners and additives. A double protective barrier can be achieved by manufacturing prepainted galvanised steels; the protection being strengthened both by the sacrificial zinc layer and by the organic barrier layer. As far as the organic barrier layer is concerned, an efficient protection is obtained by elaborating bi-layered systems consisting of a primer and a topcoat. The durability over time of such multi-layered coatings depends on their structure

Table 1

Information on the four paint coatings under study

\begin{tabular}{lllll}
\hline & $\mathrm{G}$ & $\mathrm{S}$ & $\mathrm{P}$ & $\mathrm{O}$ \\
\hline Substrate & Galvanised & Galvanised & Galvanised & Galvanised \\
steel & steel & steel & steel \\
Primer thickness & $16 \pm 2$ & $20 \pm 2$ & $7 \pm 2$ & 5 \\
$\quad(\mu \mathrm{m})$ & $17 \pm 3$ & $15 \pm 2$ & $175 \pm 15$ & 20 \\
$\begin{array}{l}\text { Top coat } \\
\text { thickness }(\mu \mathrm{m})\end{array}$ & 33 & 35 & 182 & 25 \\
$\begin{array}{c}\text { Total thickness }(\mu \mathrm{m}) \\
\text { Morphological } \\
\text { texture }\end{array}$ & Grained & Structured & Percolated & Flat \\
\hline
\end{tabular}
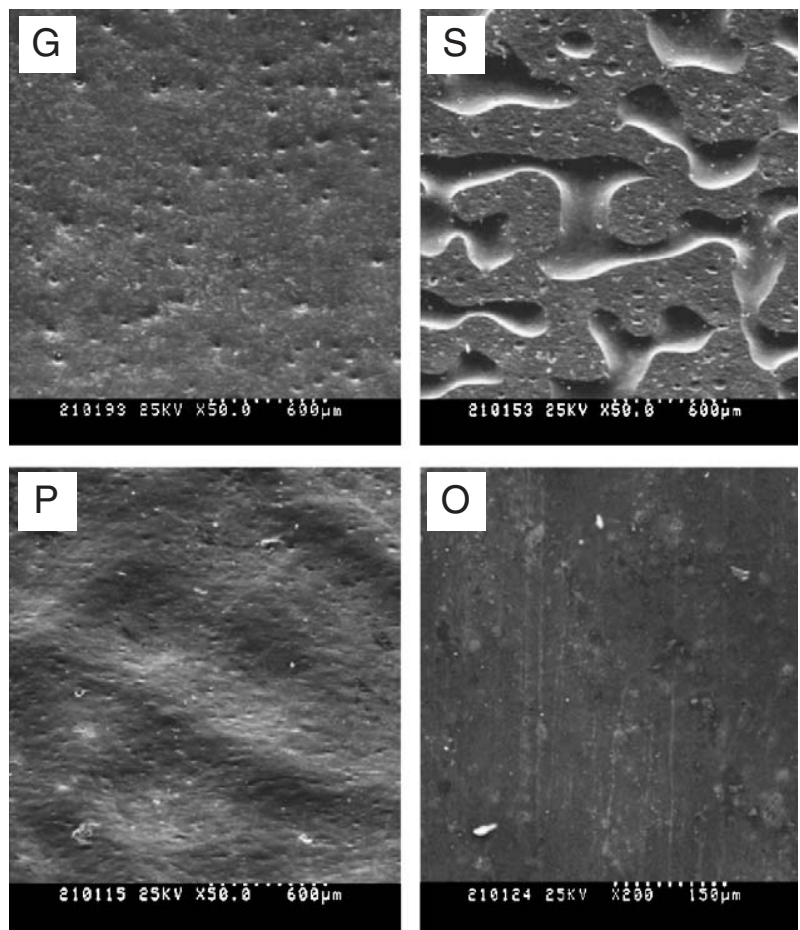

Fig. 1. SEM observations showing the morphological textures of the four paint coatings under study. G: grained texture. S: structured texture. P: percolated texture. O: flat texture.

and their properties like hardness, flexibility, friction coefficient, corrosion, wear, impact or UV resistance.

Four commercial products designed for building trade applications and manufactured by the firm Arcelor were considered in this study. These products were pre-painted galvanised steel sheets having different morphological textures which provide different aesthetic appearances. General information on these products is reported in Table 1 and their respective morphological textures are shown in Fig. 1. The products having a Grained texture, a Structured texture, a Percolated texture and a Flat texture are, respectively, denoted G, S, P and O.

\subsection{Wear testing}

Because the affected area would be too small in comparison with the heterogeneity of the morphological texture of some polymer coatings under consideration in this study, the simple «Scotch Brite» test has been preferred to usual scratch tests or micro-hardness tests [19-23]. While affecting a larger area during testing, the 'Scotch Brite test' is also more representative of damage encountered in real applications since it simulates a low wear mar damage (occurring for example during automatic car washing $[19,20]$ ). More precisely, the mar damage is due to a wear mechanism generating scratches of less than $1 \mu \mathrm{m}$ depth [19-24] that may affect the surface topography and the aspect.

The 'Scotch Brite' tests have been carried out according to the BS EN ISO 11998 standard recommendations to test the resistance to mar damage of the different polymer coatings under investigation. This normalised test uses a tribometer equipped with a 'Scotch Brite' sponge and it consists in 
applying to the sample 500 cycles without any further additional load than that of the tribometer elements supporting the abrasive sponge. Unfortunately, in the case of the polymer coatings tested in this study, the strict application of these normalised conditions produced much severe and inhomogeneous damage leading to visually non reproducible results. As a consequence, these normalised conditions were lightly modified and it was found that applying a $15 \mathrm{~N}$ load during 10 cycles allowed to obtain visually homogenous and reproducible wear damage. For each sample tested, the worn area was $4 \mathrm{~cm}$ large and $12 \mathrm{~cm}$ long.

It must be mentioned that the 'Scotch Brite' test provides only subjective information that depends in particular on the physiological perception of the practitioner since the magnitude of wear damage is visually assessed (high density of scratches, low density of scratches, no scratches). In this investigation, the mar damage has been quantitatively assessed by means of roughness and gloss measurements.

\subsection{Roughness measurements}

Surface topography of polymer coatings has been assessed before and after wear tests by means of a three dimensional (3D) tactile roughness profilometer KLA TENCOR P10. This latter device consists of a diamond tip with a $2 \mu \mathrm{m}$ rounded-end having a $10 \mathrm{~nm}$ vertical resolution according to the manufacturer. Preliminary 3D measurements have been performed to give an overview of both the as-received and worn surfaces' topographies of the different polymer coatings. Whatever the polymer coating, these preliminary measurements revealed that, for scanned areas of $20 * 20 \mathrm{~mm}$ size, the topography was isotropic in each case. Confirmed by an analysis of the bidimensional autocorrelation functions related to the different samples, these results led us afterwards to performing less time-consuming 2D measurements of $20 \mathrm{~mm}$ long profiles. Whatever the sample under consideration, fifty profiles have been recorded using a load of $5 \mathrm{mg}$, a speed rate of $200 \mu \mathrm{m} / \mathrm{s}$ and an acquisition rate of $1000 \mathrm{~Hz}$. Under these conditions, each recorded profile consists of 100,000 points equally spaced by a $0.2 \mu \mathrm{m}$ distance. These profiles were randomly recorded over the surface in the case of the as-received samples and perpendicularly to the wear scratches in the case of the worn samples.

\subsection{Gloss measurements}

The gloss of polymer coatings has been assessed before and after the wear tests. Thirty measures have been performed on each sample by means of a three-angle glossmeter DRLANGE REFO 3-D in agreement with the ASTM D523, DIN 67530 and ISO 2813 specifications. The main principle of this device is based on the idea of measuring the specular amount of reflected light directed to a surface at a specified angle from its normal. The three-angle glossmeter used in this investigation casts a white light beam at an angle of $20^{\circ}, 60^{\circ}$ or $85^{\circ}$ and a detector records the amount of reflected intensity in the specular direction (called also the mirror direction). The amount of light reflected from the surface under investigation is divided by the amount of light reflected from the surface of a reference smooth black glass plate (delivered by the manufacturer of the glossmeter) and the specular gloss is obtained by multiplying this intensity ratio by 100 . While it is recommended in the norm [25] to select a $20^{\circ}$ angle for analysing bright samples and a $85^{\circ}$ angle otherwise, gloss measurements have been carried out according to the three angles of the glossmeter $\left(20^{\circ}, 60^{\circ}\right.$ and $85^{\circ}$ ) in this investigation. Besides, these measurements have been recorded in random directions in the case of unworn coatings and in parallel and perpendicular directions with respect to the scratches' direction in the case of worn ones. These random, parallel and perpendicular directions were, respectively, denoted U, T and L.

\section{Combination of the two-way ANOVA and the CBBM}

Fig. 2 presents typical 2D profiles recorded on the surfaces of the different as-received and worn polymer coatings. At first sight, it seems that, whatever the polymer coating under consideration, the $2 \mathrm{D}$ profiles of the as-received and worn samples are very similar. As a consequence, it can be expected that the values of usual amplitude roughness parameters like the average arithmetic roughness $R_{\mathrm{a}}$ or the root-mean square roughness $R_{\mathrm{q}}$ should not allow to discriminate the unworn and worn surface topographies. The same conclusion can be drawn for the roughness parameters extracted from the well-known Abbott-Firestone curves [26] related to these profiles.

In fact, because of the numerous existing roughness parameters, it is not obvious to specify which of them is the most relevant for characterising the topography of the worn surfaces of the different polymer coatings under investigation in this study. This "parameter rash" was at the origin of the creation and development in our laboratory of a specific computer programme called MESRUG that, can firstly calculate a hundred roughness parameters and, secondly, can statistically estimate their relative relevance faced to a correlation with a particular functional property $[17,27]$. In this specific computer programme, the one-way analysis of variance (ANOVA) was used to calculate the value of the Treatment Index $F$ and the Computer Based Bootstrap Method (CBBM) to determine a confidence interval on this variable.

For this investigation, we modify our specific computer programme introducing the two-way ANOVA in combination with the CBBM with a view to finding the relevant roughness parameters for characterising the relationships between the morphological texture, the low wear resistance and the gloss of different polymer coatings. It is worth noting that, whatever the polymer coating under consideration, the roughness depends on both the type of initial morphological texture $(\mathrm{G}$, $\mathrm{S}, \mathrm{P}, \mathrm{O}$ ) and the surface state (unworn or worn).

\subsection{Traditional two-way analysis of variance and limits}

Even if the relative relevance of a hundred roughness parameters can be assessed by means of the specific software we developed, only the results related to three selected roughness 


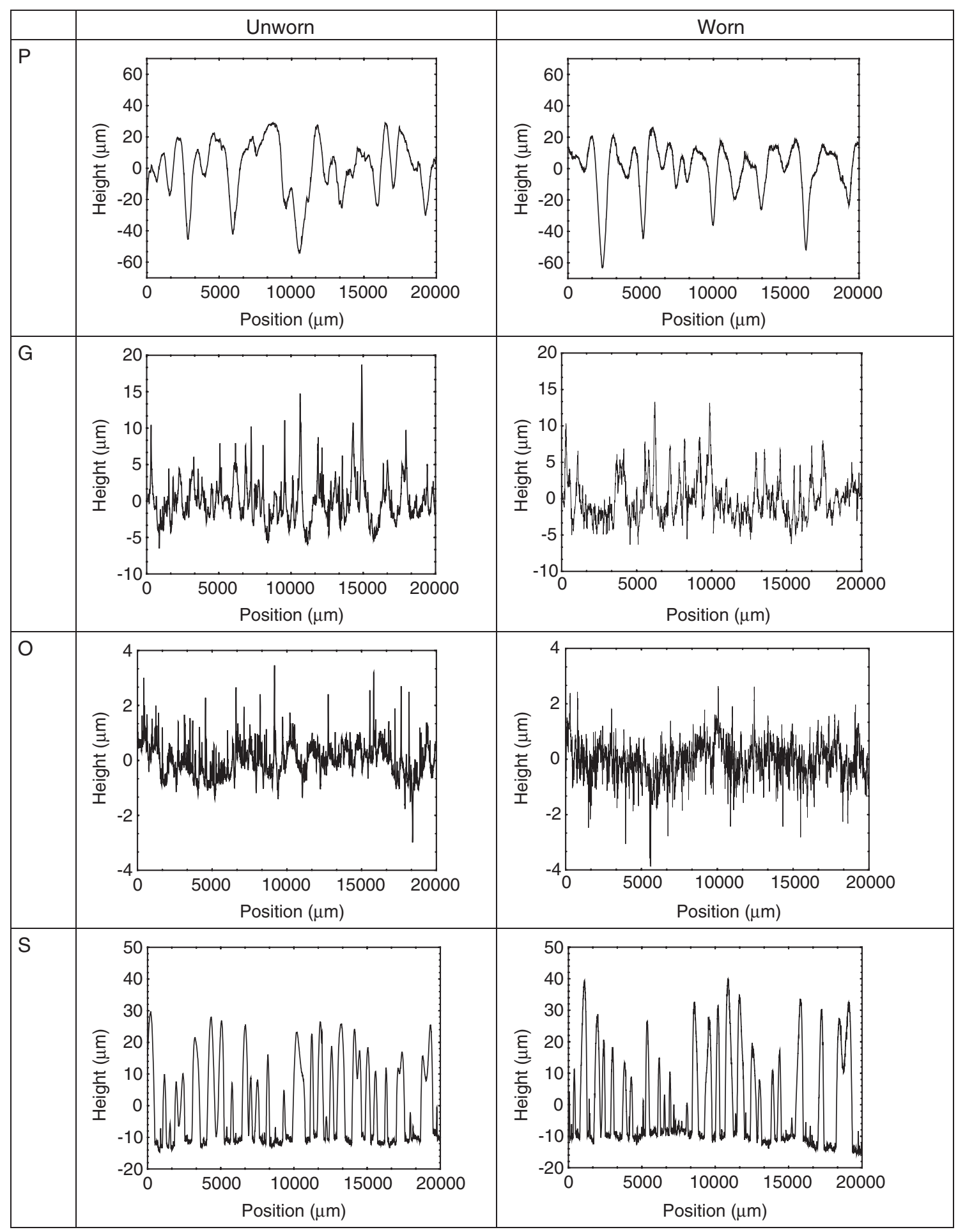

Fig. 2. Typical 2D profiles recorded on the surfaces of the different as-received (unworn) and worn polymer coatings.

parameters of interest are detailed in a first time for a sake of simplicity: the fractal dimension $\Delta_{\mathrm{ANAM}}$ calculated by a method developed by the authors [28], the average curvature radius of peaks $R_{\mathrm{wz}}$ and the average arithmetic roughness $R_{\mathrm{a}}$. The definitions of these parameters are reported in Appendix 1. Fig. 3 presents a bar chart reporting the mean values of these parameters for the different experimental conditions. At first sight, it can be concluded from this figure that, whatever the morphological structure of the polymer coating, the effect of wear damage is to increase significantly the fractal dimension $\Delta_{\mathrm{ANAM}}$ and to decrease significantly the average curvature radius of peaks $R_{\mathrm{wz}}$ without significantly affecting (as expected) the average arithmetic roughness $R_{\mathrm{a}}$ of the surfaces of the as-received samples. Besides, it can be noticed that the magnitude of the effect of wear on the recorded mean values of all these roughness parameters depend on the morphological 

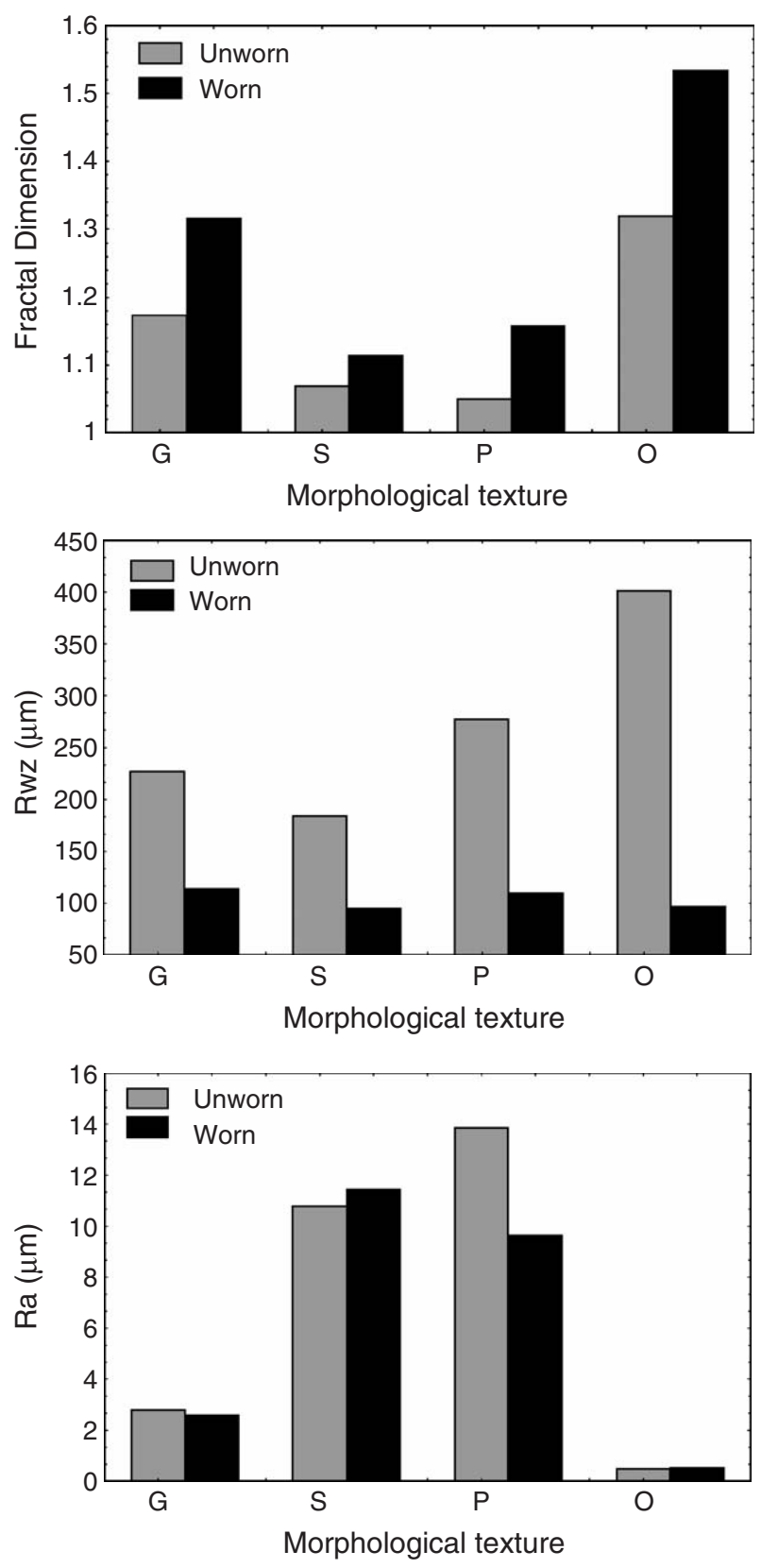

Fig. 3. Mean values of the three roughness parameters $\left(\Delta_{\mathrm{ANAM}}, R_{\mathrm{wZ}}, R_{\mathrm{a}}\right)$ recorded for the different polymer coatings (G, P, S, O) before and after the wear test.

texture of the polymer coating. Indeed, looking at the evolution of the mean values of fractal dimension $\Delta_{\mathrm{ANAM}}$ and those of the average curvature radius of peaks $R_{\mathrm{wz}}$, the morphological texture seems increasingly affected by the effect of wear according to the following ranking: $S<G \approx P<O$.

These qualitative conclusions are quantitatively confirmed by the values of the Treatment Index $F^{\text {Effect }}$ resulting from the two-way ANOVA whose philosophy is briefly summarised in Appendix 2. The higher the value of $F^{\mathrm{Effect}}$ related to a roughness parameter, the higher its relevance with regard to the treatment effect under consideration. For more details on the two-way ANOVA, the reader should refer to Ref. [29]. According to the ranking of $F^{\mathrm{Effect}}$ values $\left(F_{R \mathrm{wz}}^{\mathrm{Wear}}=42,203>F_{\mathrm{ANAM}}^{\mathrm{Wear}}=\right.$
$\left.17,706>F_{R \mathrm{a}}^{\mathrm{Wear}}=187\right)$ reported in Table 2, it can be deduced that, independently of the morphological texture of the polymer coating, the average curvature radius of peaks $R_{\mathrm{wz}}$ is the most relevant roughness parameter for describing the effect of wear on the topography of the as-received samples. In the same way, independently of any effect of wear, the fractal dimension $\Delta_{\mathrm{ANAM}}$ is the most relevant parameter for describing the morphological texture of the different polymer coatings $\left(F_{\text {ANAM }}^{\text {Text. }}=\right.$ $\left.24,803>F_{R \mathrm{a}}^{\text {Text. }}=6900>F_{R \mathrm{wz}}^{\text {Text. }}=3030\right)$. Besides, the effect of interaction (synergy between the morphological texture and the wear) is the most significant for the average curvature radius of peaks $R_{\mathrm{wz}}\left(F_{R \mathrm{a}}^{\mathrm{Int}}=248<F_{\mathrm{ANAM}}^{\mathrm{Int}}=1278<F_{R \mathrm{wz}}^{\mathrm{Int}}=3395\right)$ while being however less significant than the main effect of wear itself.

However, it must be emphasised that the reliability of these results theoretically depends on whether the inferred assumptions related to the two-way ANOVA are valid or not. Indeed, this traditional statistical method is based on the assumption that the variable $F^{\text {Effect }}$ follows a Fisher-Snedecor law. More precisely, to affirm that the assessed $F^{\text {Effect }}$ value is statistically higher than unity, the underlying Fisher-Snedecor test used in the two-way ANOVA assumes that recorded measurements under the different experimental conditions (roughness on each polymer coating in the as-received state and after the wear test in this study) follow Gaussian laws (assumption of normality) having similar standard deviations (assumption of homoscedasticity of variance). Unfortunately, the number of statistical tests, which have to be performed to verify these assumptions is proportional to the number of roughness parameters under consideration. If only one of these tests was rejected, it should be concluded that the related variable $F^{\text {Effect }}$ do not follow a Fisher-Snedecor probability density function and therefore the two-way ANOVA should not have been processed. Since the overall number of roughness parameters is about one hundred in this investigation, it is not conceivable to perform such a high number of tests (100 roughness parameters $* 2 * 4=800$ tests!!! for verifying the assumption of normality), which means that in practice the risk of violating the two-

Table 2

Results of the two-way ANOVA related to the roughness parameters $R_{\mathrm{a}}, \Delta_{\mathrm{ANAM}}$ and $R_{\mathrm{wz}}$

\begin{tabular}{|c|c|c|c|c|c|}
\hline & $\begin{array}{l}\text { Degree of } \\
\text { freedom }\end{array}$ & Mean square & $\begin{array}{l}\text { Degree of } \\
\text { freedom }\end{array}$ & Mean square & $F$ \\
\hline & Effect & Effect & Error & Error & \\
\hline \multicolumn{6}{|l|}{$R_{\mathrm{a}}$} \\
\hline Texture & 3 & 6914 & 892 & 1 & 6900 \\
\hline Wear & 1 & 187 & 892 & 1 & 187 \\
\hline Interaction & 3 & 249 & 892 & 1 & 248 \\
\hline \multicolumn{6}{|l|}{$\Delta_{\text {ANAM }}$} \\
\hline Texture & 3 & 4.89 & 892 & $2.10^{-4}$ & 24,803 \\
\hline Wear & 1 & 3.47 & 892 & $2.10^{-4}$ & 17,601 \\
\hline Interaction & 3 & 0.25 & 892 & $2.10^{-4}$ & 1278 \\
\hline \multicolumn{6}{|l|}{$R_{\mathrm{wz}}$} \\
\hline Texture & 3 & 434,082 & 892 & 143 & 3030 \\
\hline Wear & 1 & $6,045,445$ & 892 & 143 & 42,203 \\
\hline Interaction & 3 & 486,394 & 892 & 143 & 3395 \\
\hline
\end{tabular}


way ANOVA assumptions increases as well as the consequent risk of asserting false conclusions. Besides, even if the inferred hypotheses in two-way ANOVA are supposed to be satisfied, this conventional statistical theory does not consider the subtle fact that a small perturbation in any original score may affect the value of the Treatment Index $F^{\text {Effect }}$; value resulting from the calculation of mean quantities. In other terms, the ANOVA does not provide any confidence interval on the advanced value of Treatment Index $F^{\text {Effect }}$. Under these conditions, we might wonder if the values of $F^{\text {Effect }}$ we previously advanced and compared in our illustrated example were significantly different or not; i.e. if our conclusions were reliable or not.

These limits related to the traditional way of statistical analysis is at the origin of our proposal of an alternative statistical methodology based on the combination of the two-way ANOVA and the powerful Computer-Based Bootstrap Method (CBBM). For each roughness parameter $P_{i}$, the two-way ANOVA is used to estimate the Treatment Indexes $F_{i}^{\text {Effect }}$ and the CBBM to determine a confidence interval on these variables. Roughly speaking, the CBBM allows the replacement of statistical inference assumptions about the underlying population under study by intensive computation. For more details on the CBBM, the reader should refer to Refs. [17,30-32].

\subsection{Application of the CBBM in the absence of effects}

An oversimplified example is here presented for a better understanding of the CBBM. In a first time, an arbitrary selected roughness parameter $P$ has been assumed to be irrelevant with regard to the initial morphological texture of the polymer coating whatever the surface state (unworn/worn). This means that, for each surface state, the recorded experimental values of this considered roughness parameter are assumed to be statistically the same whatever the initial morphological texture. Under these conditions, for each surface state, all these values related to the different initial morphological textures can be gathered in a single dataset before applying the mathematical operations of random sampling with replacement involved in the CBBM. A schematic example of Bootstrap sample that could be generated by this way is presented in Table 3. Of course, such a method can be reproduced to generate the number of Bootstrap samples $N$ the practitioner wishes to study. Any statistical method of interest can be further applied onto each simulated Bootstrap sample which represents the effect of a perturbation affecting the experimental dataset.

This methodology has been applied for all the roughness parameters $P_{i}$ considered in this investigation. For each roughness parameter $P_{i}$ and each effect or interaction, the two-way ANOVA has been applied onto each simulated Bootstrap sample $n(n \in[1$ to $N])$ to plot an empirical PDF consisting of $N(N=10,000$ in this study) simulated values $\left\{\left(F^{0}\right)_{i}^{n} ; n \in[1, N]\right\}$. Then, the values of the mean $-\left(\overline{F^{0}}\right)_{i}$, the 5 th percentile $\left(F^{0}\right)_{i}^{5 \%}$ and the 95 th percentile $\left(F^{0}\right)_{i}^{95 \%}$ have been extracted from this empirical PDF to assess the central tendency and the deviation through the calculation of the $90 \%$ confidence level. Fig. 4 a presents examples of PDF obtained for $R_{\mathrm{wz}}, R_{\mathrm{a}}$ and $\Delta_{\mathrm{ANAM}}$ when assuming that these roughness parameters are not relevant with regard to the initial morphological texture independently of the surface state (unworn/worn). In the same way, Fig. $4 \mathrm{~b}$ presents examples of PDF of the same roughness parameters when assuming that they are not relevant with regard to the surface state independently of the initial morphological texture.

\subsection{Application of the CCBM in the possible presence of effects}

In a second time, no preconceived opinion has been considered on the relevance of the arbitrary selected roughness parameter $P$ with regard to either the initial morphological texture of the polymer coating or the surface state (unworn/worn). Under these conditions, the mathematical operations of random sampling with replacement involved in the CBBM can be only performed on the data corresponding to each specific experimental conditions. A schematic example of Bootstrap data that could be generated by this way is also presented in Table 3 .

For each roughness parameter $P_{i}$ considered in this investigation, $N=10,000$ Bootstrap samples have been generated by this method and subsequently processed using the two-way ANOVA. Examples of PDF obtained for the roughness parameters $R_{\mathrm{wZ}}, R_{\mathrm{a}}$ and $\Delta_{\mathrm{ANAM}}$ are presented in Fig. $5 \mathrm{a}$ and $\mathrm{b}$ considering the effect of either the morphological texture or the wear. For each effect, the mean, the 5th and 95th percentiles

Table 3

Example of a possible bootstrap sample generated either by (a) assuming that the roughness parameter $P$ is irrelevant with regard to the initial morphological texture or the surface state, or (b) without any preconceived opinion on the relevance of the roughness parameter $P$ with regard to the initial morphological texture and the surface state

\begin{tabular}{|c|c|c|c|c|c|c|}
\hline & \multicolumn{3}{|c|}{ As-received (unworn) samples } & \multicolumn{3}{|c|}{ Worn samples } \\
\hline & Texture 1 & Texture 2 & Texture 3 & Texture 1 & Texture 2 & Texture 3 \\
\hline Experimental data of $P$ & $1.3,1.4,1.8$ & $1.1,1.5,1.3$ & $1.6,1.2,1.4$ & $1.2,1.6,1.2$ & $1.9,1.8,1.7$ & $1.1,1.2,1.4$ \\
\hline \multicolumn{7}{|c|}{$P$ is irrelevant with regard to the initial morphological texture (whatever the surface state). } \\
\hline Bootstrapped sample & $1.5,1.2,1.2$ & $1.3,1.8,1.1$ & $1.4,1.5,1.3$ & $1.2,1.8,1.4$ & $1.2,1.1,1.6$ & $1.1,1.9,1.6$ \\
\hline \multicolumn{7}{|c|}{$P$ is irrelevant with regard to the surface state (whatever the initial morphological texture). } \\
\hline Bootstrapped sample & $1.6,1.2,1.4$ & $1.5,1.8,1.1$ & $1.6,1.4,1.1$ & $1.3,1.8,1.3$ & $1.9,1.3,1.1$ & $1.2,1.2,1.6$ \\
\hline \multicolumn{7}{|c|}{ No preconceived opinion on the relevance of $P$. } \\
\hline Bootstrapped sample & $1.4,1.4,1.3$ & $1.5,1.5,1.1$ & $1.4,1.2,1.6$ & $1.2,1.2,1.2$ & $1.8,1.8,1.7$ & $1.1,1.1,1.4$ \\
\hline
\end{tabular}


extracted from the three PDF are reported in Fig. 6 as well as the values of the same statistics related to the overall studied roughness parameters. The mean values and the $90 \%$ confidence intervals of a hundred roughness parameters are thus ranked in an increasing order in this figure; i.e. in an increasing order of relevance level with regard to the effect analysed. The similar statistics (denoted $F^{0}$ in the figure) but extracted from the PDFs previously obtained assuming the absence of effects are also reported in this figure.

It is worth noting that, whatever the effect studied, most of the roughness parameters are relevant since the $90 \%$ confidence intervals related to their $F^{\text {Effect }}$ values are always strictly above the corresponding $90 \%$ confidence intervals assessed in the absence of effect. However, many parameters have the same relevance level with regard to each analysed effect since an overlap of their respective $90 \%$ confidence intervals can be noticed. Besides, it can be seen on this figure that, whatever the effect analysed, the most commonly used roughness parameter $R_{\mathrm{a}}$ is never the most relevant. Finally, the overall results presented in Fig. 6 show that: (a) among approximately a hundred studied roughness parameters, the fractal dimension $\Delta_{\mathrm{ANAM}}$ is the most relevant one for characterising the different morphological textures of polymer coatings under study whereas the average curvature radius of peaks $R_{\mathrm{wz}}$ is the most relevant one for characterising the worn surfaces, (b) the effect of interaction is more significant for the average curvature radius of peaks $R_{\mathrm{wz}}$ than for the fractal dimen$\operatorname{sion} \Delta_{\mathrm{ANAM}}$, (c) the effect of interaction is less significant than the

\section{(a) Absence of initial morphological texture effect}
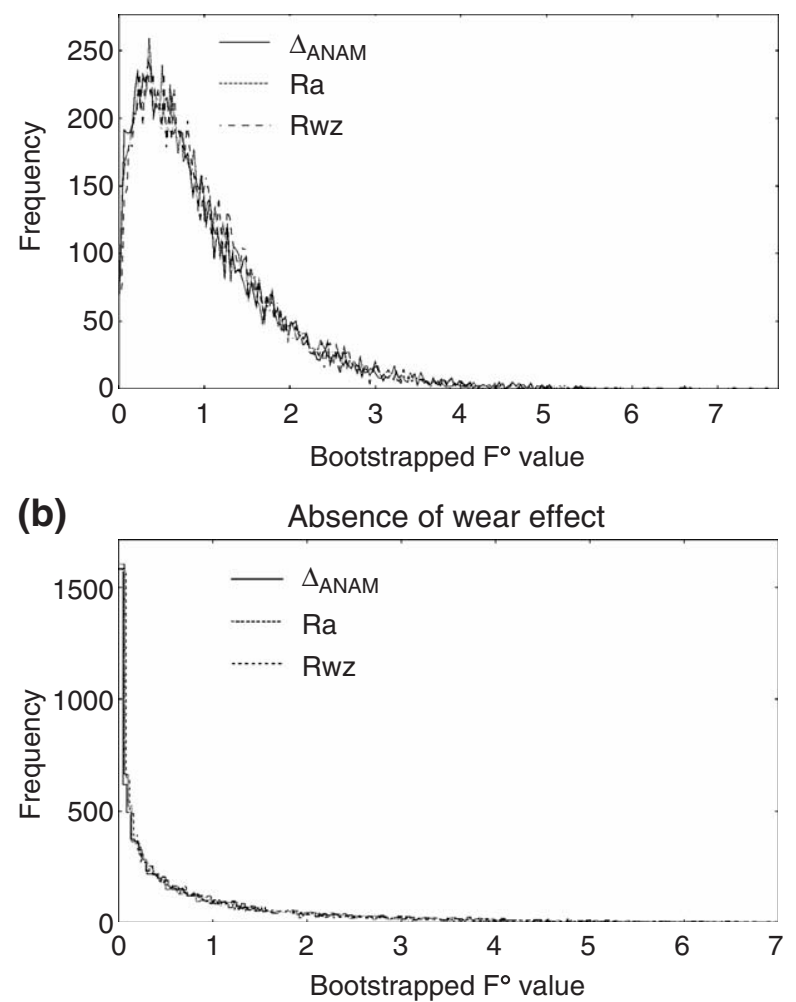

Fig. 4. PDFs of the Bootstrapped $F^{0}$ values obtained for the three roughness parameters ( $\Delta_{\mathrm{ANAM}}, R_{\mathrm{wz}}, R_{\mathrm{a}}$ ) assuming that they are irrelevant with regard to: (a) the initial morphological texture of the polymer coating, (b) the wear.
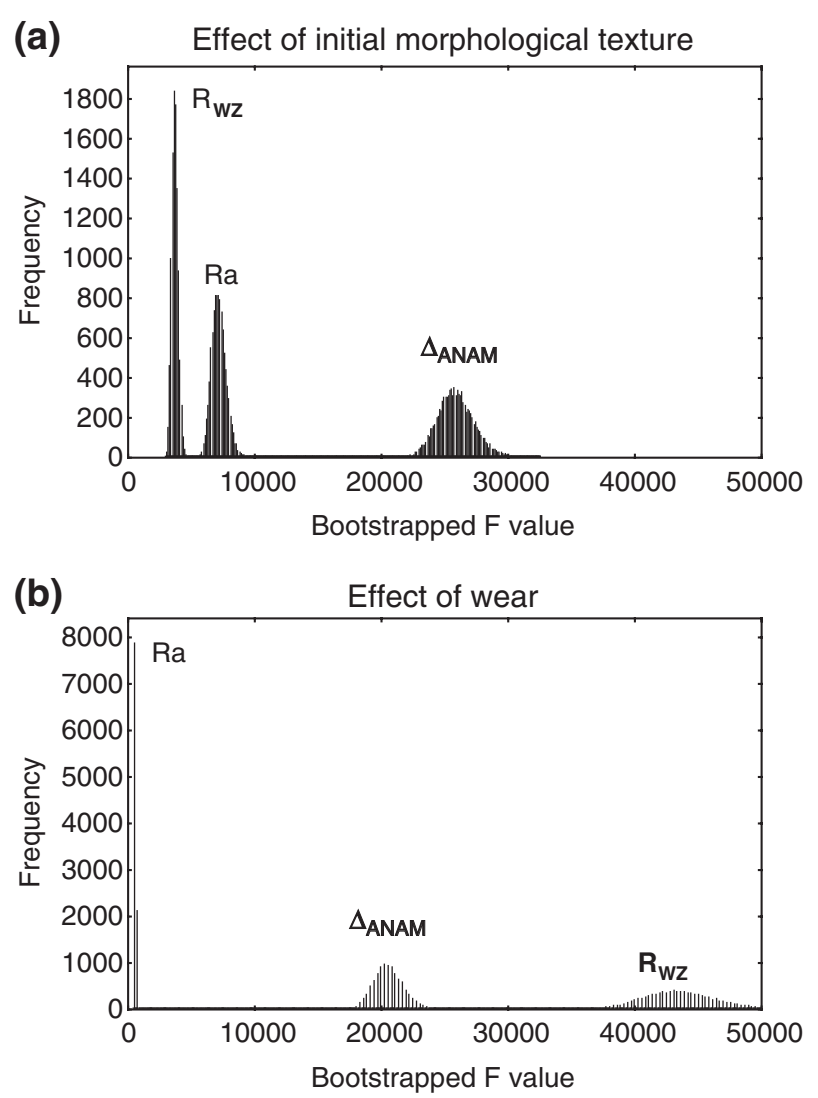

Fig. 5. PDFs of the Bootstrapped $F^{\text {Effect }}$ values obtained for the three roughness parameters $\left(\Delta_{\mathrm{ANAM}}, R_{\mathrm{wZ}}, R_{\mathrm{a}}\right)$ when analysing the effect of: (a) the initial morphological texture of the polymer coating, (b) the wear

main effect of wear for the average curvature radius of peaks $R_{\mathrm{wz}}$ which is the most relevant roughness parameter for characterising the worn surfaces.

\section{Gloss of polymer coatings}

\subsection{Relationship between gloss and wear}

Fig. 7 presents the influence of the glossmeter angle $\left(20^{\circ}\right.$, $60^{\circ}$ and $85^{\circ}$ ) on the different mean values of gloss recorded on the surface of each polymer coating before and after the wear test. This figure shows that, whatever the selected glossmeter angle, the mean gloss of the worn coatings is lower than that of the unworn ones. Moreover, the lower the angle of the reflected white light beam with respect to the surface sample, the higher the mean values of the recorded gloss of the different unworn and worn coatings. Besides, whatever the selected glossmeter angle and the morphological texture, the mean gloss values of worn coatings are statistically the same for measurements performed with the light beam of the glossmeter oriented either in the parallel ( $L$ orientation) or in the perpendicular ( $T$ orientation) direction with respect to the scratches direction.

As for the roughness measurements, similar two-way ANOVA data treatments have been performed for the gloss measurements. Table 4 presents the two-way ANOVA results related to a test of the effects of either the coating morphological texture or the wear (independently of the orientation of the 

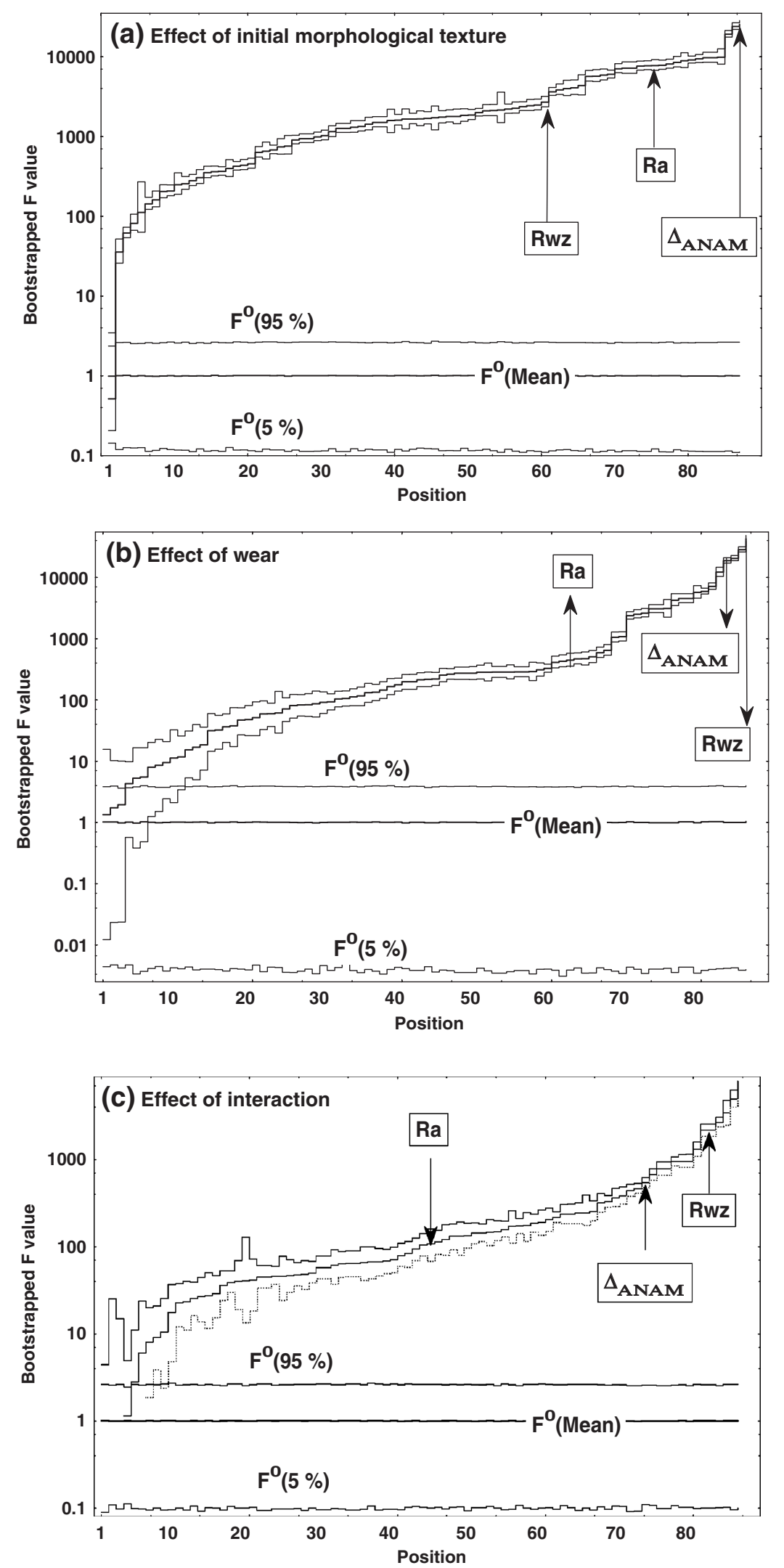

Fig. 6. Statistics (mean and 90\% confidence interval) related to the Bootstrapped $F$ values obtained for all the roughness parameters when analysing the effect of: (a) the initial morphological texture of the polymer coating, (b) the wear, (c) interaction (synergy). $F^{0}$ represents the similar statistics assuming the absence of the effect under consideration. 

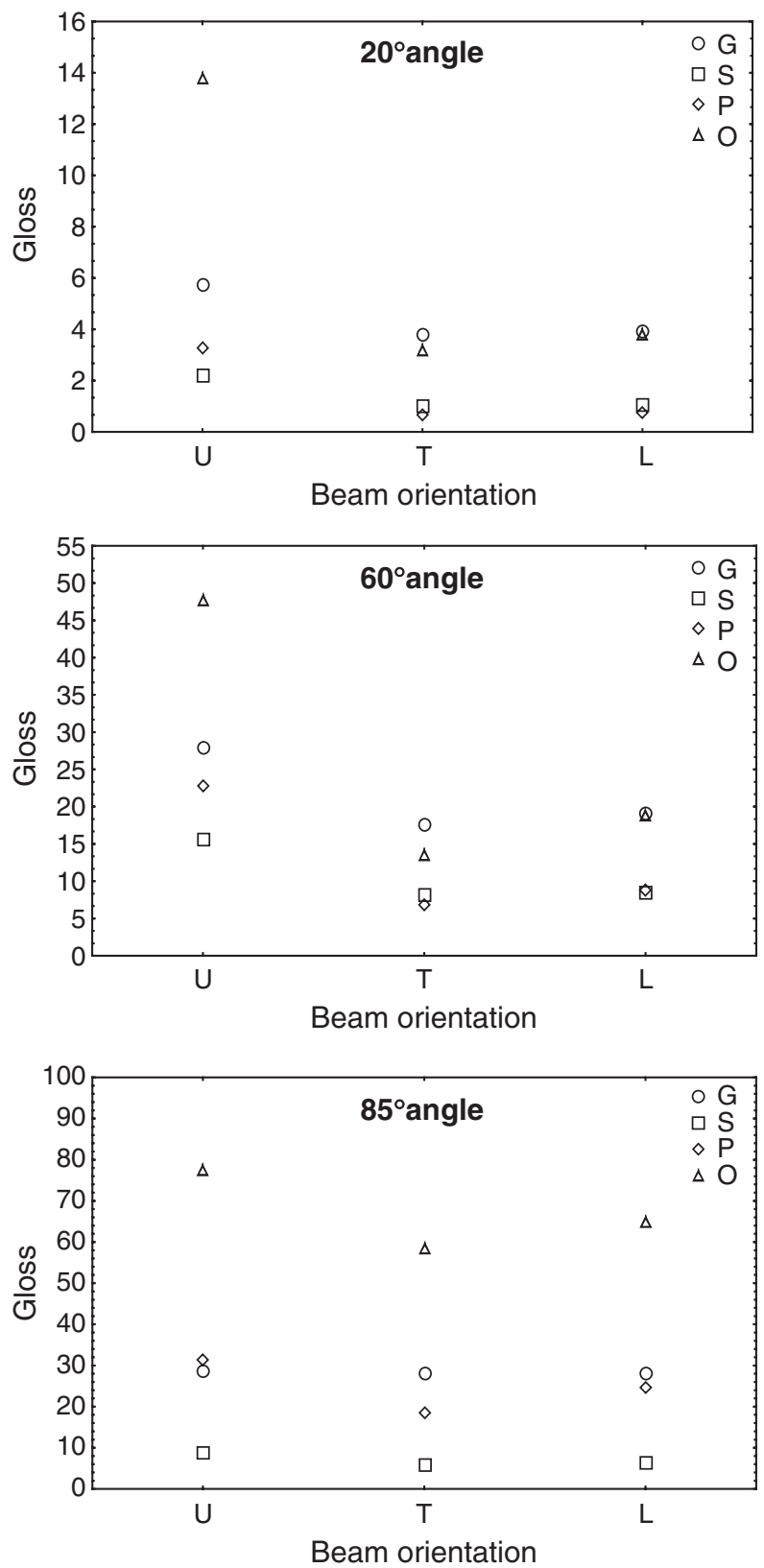

Fig. 7. Influence of the glossmeter angle $\left(20^{\circ}, 60^{\circ}\right.$ and $\left.85^{\circ}\right)$ on the different mean values of gloss recorded on the surface of each polymer coating before and after the wear test. U, T and L correspond to gloss measurements, respectively, carried out casting the white light beam of the glossmeter randomly on the surface of the unworn polymer coatings, perpendicularly and in a parallel direction to the scratches of the worn polymer coatings.

scratches in a first time meaning that the results for the $\mathrm{T}$ and $\mathrm{L}$ conditions have been gathered for this two-way ANOVA treatment) on the mean gloss recorded for the different glossmeter angles of measurement. These results show that, firstly, the effect of the morphological texture of the coating dominates at an $85^{\circ}$ angle; i.e. at a small angle of the reflected white light beam with respect to the surface. Secondly, the effect of wear dominates at a $20^{\circ}$ angle; i.e. at a small angle of the reflected white light beam with respect to the surface perpendicular. Table 5 presents the two-way ANOVA results related to a test on the effects of the coating morphological texture and orien-
Table 4

Two-way ANOVA results showing the relative effects of morphological texture and wear on the gloss of polymer coatings recorded at $20^{\circ}, 60^{\circ}$ and $85^{\circ}$ angles

\begin{tabular}{lrlr}
\hline Effect & $F_{20^{\circ}}$ & $F_{60^{\circ}}$ & $F_{85^{\circ}}$ \\
\hline Morphological texture & 8387 & 2113 & 9425 \\
Wear & 12,545 & 6662 & 726 \\
\hline
\end{tabular}

tation of the scratches on the mean gloss recorded for the different glossmeter angles of measurement. These results show that, whatever the selected glossmeter angle, the effect of the morphological texture on the gloss is highly dominant in comparison with that of the orientation of the scratches. Moreover, whatever the effect considered, the most discriminating experimental conditions of gloss measurements are obtained using the lower angle of the reflected white light beam with respect to the sample surface.

\subsection{Relation between gloss and the roughness parameter}

It was shown in this investigation that, whatever the morphological texture of the polymer coating,:

a) the average curvature radius of peaks $R_{\mathrm{wz}}$ is the most relevant roughness parameter for describing the effect of wear on the topography of the as-received samples,

b) one effect of wear is to reduce the gloss.As a consequence, it seems obvious to study the relationships between these surface properties for the different polymer coatings under consideration. For each polymer coating and each retained glossmeter angle, the reduction observed in the mean values of these surface properties due to wear is simply calculated using the following equations:

$$
\begin{aligned}
& \delta R_{\mathrm{wz}}=\left(R_{\mathrm{wz}}\right)_{\mathrm{as}-\text { received }}-\left(R_{\mathrm{wz}}\right)_{\mathrm{worn}} \\
& \delta \text { Gloss }=(\text { Gloss })_{\mathrm{as}-\text { received }}-(\text { Gloss })_{\mathrm{worn}} .
\end{aligned}
$$

Fig. 8 shows the evolution of the reduction of gloss $\delta$ Gloss recorded for the three angles of the glossmeter as a function of the reduction of the average curvature radius of peaks $\delta R_{\mathrm{wz}}$. Whatever the glossmeter angle, a linear relationship is observed between these properties; the reduction of gloss is proportional to the reduction of the average curvature radius of peaks. It is worth noting that this relationship is quite obvious for gloss measurements carried out at a $60^{\circ}$ angle; an intermediate angle comprised between a $20^{\circ}$ angle for which the effect of wear is dominant and a $85^{\circ}$ angle for which the effect of the morphological texture is dominant on the gloss of the polymer coatings.

Table 5

Two-way ANOVA results showing the relative effects of morphological texture and scratches orientation on the gloss of polymer coatings recorded at $20^{\circ}, 60^{\circ}$ and $85^{\circ}$ angles

\begin{tabular}{lrrr}
\hline Effect & $F_{20^{\circ}}$ & $F_{60^{\circ}}$ & \multicolumn{1}{c}{$F_{85^{\circ}}$} \\
\hline Morphological texture & 2685 & 1633 & 23,779 \\
Scratches orientation & 50 & 267 & 451 \\
\hline
\end{tabular}




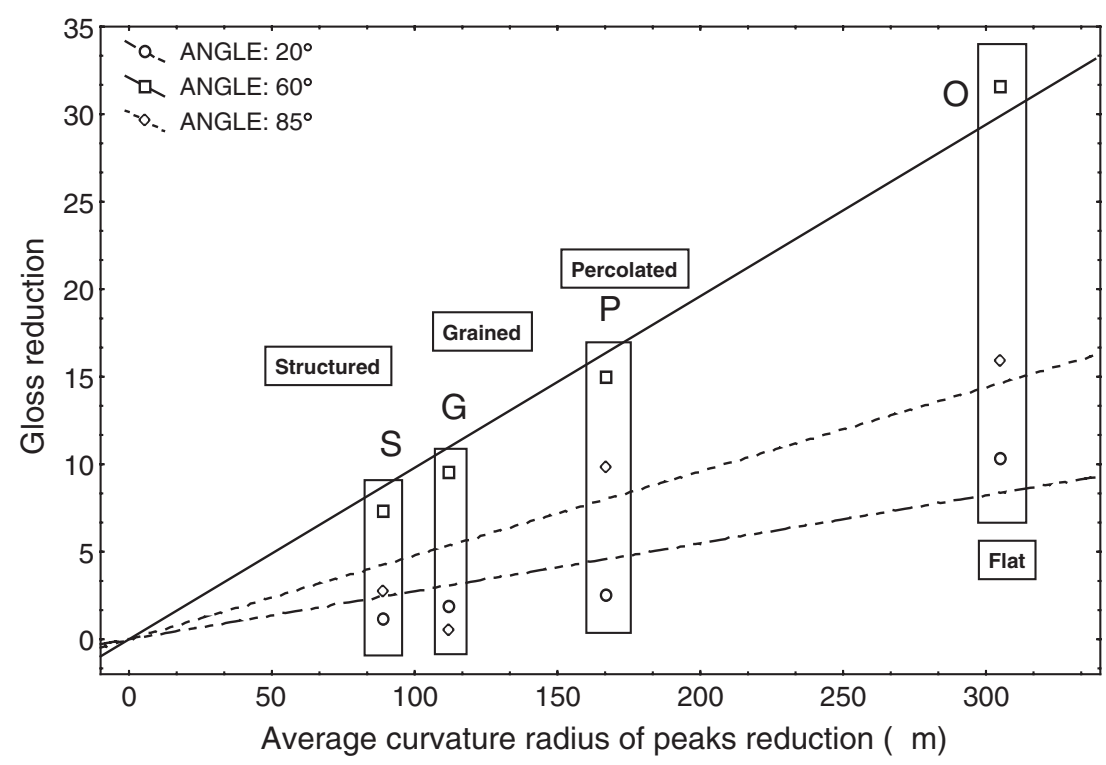

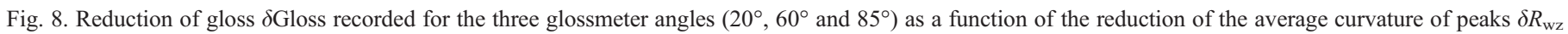
noticed for the different polymer coatings.

This figure indicates that, for the short duration mechanical tests carried out under low load in this investigation, the paint coating morphological texture is increasingly affected according to the following ranking: $S<G<P<O$.

\section{Discussion}

Because of the observed linear correlation with the reduction of the average curvature radius of peaks $\delta R_{\mathrm{wz}}$, it can be concluded that the reduction of gloss reduction $\delta$ Gloss of the studied paint coatings is simply related to the modification of the texture micro-roughness due to the wear damage; the magnitude of the reduction of both the average curvature radius of peaks and the related gloss depending on the initial morphological texture (macro-roughness).

It must be mentioned that, during the short duration mechanical tests carried out under low load in this investigation, no debris generation was noticed and the longitudinal scratches observed are therefore due very probably to the simple ploughing action of the hard abrasive particles contained in the 'Scotch Brite' sponge. This ploughing action is thought to affect mainly the top of the asperities supporting the contact stresses. At the top of these asperities, abrasive particles locally penetrate by plastic deformation in the tested soft polymer coating and new local peaks are likely to be generated. As illustrated in Table 6, these new local peaks due to scratching necessarily have a lower local curvature radius than that of the affected asperity under consideration. The higher the curvature radius of the asperities related to the initial morphological texture, the higher their probability to be scratched by abrasive particles during the wear test. Since the final values of the average radius of peaks recorded becomes similar after the wear test independently of the polymer coating under investigation, it is strongly suspected that the penetration depth is of the same order of magnitude (less than $0.5 \mu \mathrm{m}$ ) whatever the initial morphological texture. In other words, under the selected experimental conditions (short duration tests, low load, soft polymer coatings), the final texture micro-roughness is suspected to be similar whatever the initial texture macro-roughness of the polymer coating under consideration. This suspicion is in agreement with SEM observations showing very similar damage at low scales whatever the polymer coating (Fig. 9). As a consequence, under the selected experimental conditions for which the ploughing action of abrasive particles mainly affects the texture micro-roughness, the magnitude of the reduction of the average curvature radius of peaks $\delta R_{\mathrm{wz}}$ noticed after wear tests simply depends on the value of the average curvature radius of peaks related to the initial morphological texture of the polymer coating under consideration. This can explain why the value of $\delta R_{\mathrm{wz}}$ is increasingly affected for the polymer coatings under consideration according to the following ranking: $S<G<P<O$.

Such a damage mechanism is fully in agreement with the experimental facts showing that, in comparison with an unworn sample, (a) the average curvature radius of peaks value of a worn sample should be reduced, (b) the higher is the value of the peaks average curvature radius related to the initial

Table 6

Schematic representation of the effect of abrasive particles at the top of an asperity having either a high or a small average radius of curvature depending on the initial morphological texture of the polymer coating under consideration

\begin{tabular}{l}
\hline $\begin{array}{l}\text { Initial morphology } \\
\text { (before the wear test) }\end{array}$ \\
$\begin{array}{l}\text { Small average } \\
\text { curvature } \\
\text { radius }\end{array}$ \\
$\begin{array}{l}\text { High average } \\
\text { curvature } \\
\text { radius }\end{array}$
\end{tabular}

Arrows points the locations where abrasive particles penetrate at the top of the asperity. 

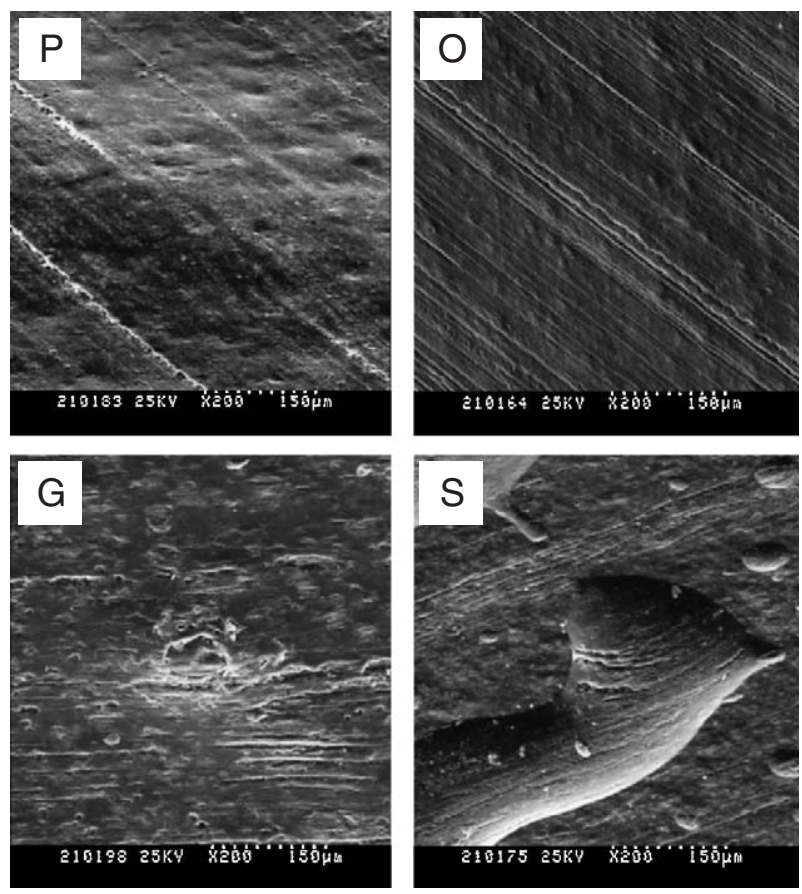

Fig. 9. Scanning Electron Microscope observations at low scales of the different polymer coatings surface topography after wear tests. Note that wear damage is similar whatever the initial morphological texture of the polymer coating under consideration.

morphological texture of the polymer coating, the higher should be the magnitude of the reduction, (c) the fractal dimension (which traduces the chaotic aspect of the profiles) of a worn sample should be increased. Moreover, since only the micro-roughness of the polymer coatings was affected during the selected experimental conditions of this study, it is not surprising that any difference had been visually observed at large scale between 2D unworn and worn profiles and any difference had been observed between the mean values of the average arithmetic roughness $R_{\mathrm{a}}$ which integrates the texture macro-roughness $(2 \mathrm{D}$ profiles had not been filtered in this investigation before their numerical treatment).

\section{Conclusion}

In this paper, we presented an original and efficient methodology for assessing without any preconceived opinion the relative relevance of a hundred roughness parameters with regard to the relationships between the morphological texture, the low wear resistance and the gloss of polymer coatings. For each roughness parameter, this methodology consists in combining the two-way ANOVA and the Computer-Based Bootstrap Method (CBBM), respectively, to calculate statistical indexes of performance $F$ and to determine a confidence interval on this variable.

The fractal dimension and the average curvature radius of peaks were shown to be the most relevant roughness parameters for characterising, respectively, the morphological texture of polymer coatings and the effect of wear. Besides, it was outlined that a $85^{\circ}$ angle is more relevant for characterising the effect of the morphological texture on the gloss measurements while a $20^{\circ}$ angle is more relevant for characterising the effect of wear. Finally, it was shown that, for the four polymer coatings under study, the low wear generated during the 'Scotch Brite' test induced a reduction of the gloss linearly proportional to the related reduction of the average curvature radius of peaks. Under the selected experimental conditions, this low wear is thought to be due to the ploughing action of the abrasive particle contained in the 'Scotch Brite' sponge. This ploughing mechanism affects mainly the micro-roughness texture whatever the initial morphological texture of the polymer coatings studied.

Based on statistical tools and on the power of modern computers, this new methodology is thought to be generic to study, without any preconceived opinion, any relationship between the roughness parameters of a surface and a specific physical or functional property.

\section{Acknowledgements}

The authors would like to thank B. Cromières and C. Dessain for supplying us the samples of this study and for helpful discussions, the firm Arcelor for permission to publish the results and V. Hague for proof-reading this paper.

\section{Appendix A}

\section{A.1. The arithmetic roughness parameter $R_{a}$}

This most commonly used roughness parameter represents the absolute deviation from the profile heights and the reference mean line. This amplitude roughness parameter is defined such that:

$R_{\mathrm{a}}=\frac{1}{l} \int_{0}^{l}|z(x)| \mathrm{d} x$

where $l$ is the evaluation length and $z(x)$ is the profile height relative to the reference mean line at position $x$.

\section{A.2. The average curvature radius of peaks $R_{w z}$}

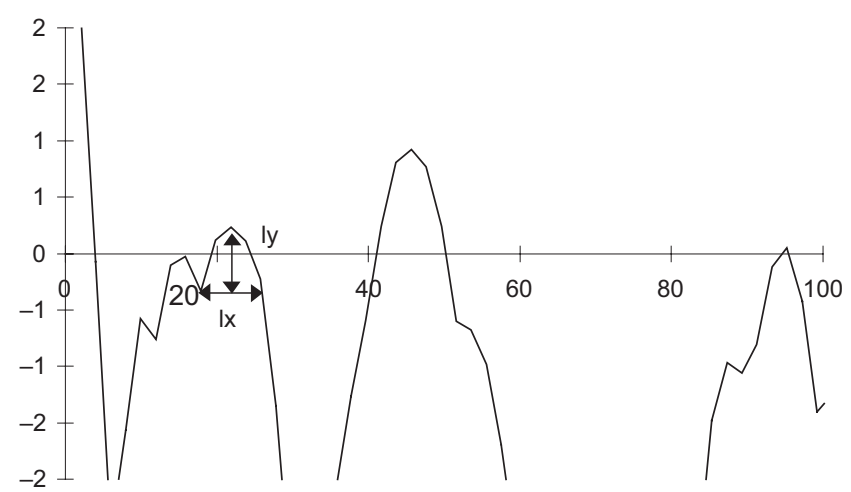

Let us consider the local curvature radius of a peak assumed to be spherical such that $r_{i}=\frac{\left(l_{x_{i}}\right)^{2}}{8 l_{y_{i}}}$.

The average curvature radius of peaks detected along a profile is given by $R_{\mathrm{wz}}=\sum_{i=l}^{k} r_{i} / k$ where $k$ is the number of peaks detected. 


\section{A.3. The fractal dimension $\triangle_{A N A M}$ estimated by the ANAM method}

Let us consider $a<b$ where $a$ and $b$ are two real numbers, $f$ a $C^{0}$ function such that $f:[a-\tau, b+\tau] \rightarrow I R, x \rightarrow f(x)$. Let us generalise the structure function with $\alpha$ a real number higher than unity and define $M_{\tau}^{\alpha}(f, x)$ as follows:

$M_{\tau}^{\alpha}(f, x)=\left[\frac{1}{\tau^{2}} \int_{t_{1}=0}^{\tau} \int_{t_{2}=0}^{\tau}\left|f\left(x+t_{1}\right)-f\left(x-t_{2}\right)\right|^{\alpha} \mathrm{d} t_{1} \mathrm{~d} t_{2}\right]^{\frac{1}{\alpha}}$

By averaging $M_{\tau}^{\alpha}(f, x)$ on the overall profile length $L$, the $K_{\tau}^{\alpha}(f$, $L$ ) function is formally obtained:

$K_{\tau}^{\alpha}(f, L)=\frac{1}{L} \int_{x=0}^{x=L}\left[\frac{1}{\tau^{2}} \int_{t_{1}=0}^{\tau} \int_{t_{2}=0}^{\tau}\left|f\left(x+t_{1}\right)-f\left(x-t_{2}\right)\right|^{\alpha} \mathrm{d} t_{1} \mathrm{~d} t_{2}\right]^{\frac{1}{\alpha}} \mathrm{d} x$

The numerical form of this equation is given below:

$\hat{K_{k}^{\alpha} \delta}(f, n)=\frac{(k+1)^{-\frac{2}{\alpha}}}{n-2 k} \sum_{i=k+1}^{n-k}\left[\sum_{j=0}^{k} \sum_{l=0}^{k}\left|f_{i+j}-f_{i-l}\right|^{\alpha}\right]^{\frac{1}{\alpha}}$

where $n=L \delta x$ is the number of discretized consecutive points equally spaced of a distance $\delta x=x_{i+1}-x_{i}$ on the overall profile length $L$.

If the considered function $f$ is assumed to be Hölderian and anti-Hölderian, it can be shown that:

$\Delta(f, L)=\lim _{\tau \rightarrow 0}\left(2-\frac{\log K_{\tau}^{\alpha}(f, L)}{\log \tau}\right)$.

Finally, the fractal dimension is assessed using the linear least square method to calculate the slope of the plot $\log \hat{K}_{k \delta x}^{\alpha}(f$, $n)$ versus $\log (k \delta x)$ for various $k \delta x$ values; this slope corresponds to the Hölder exponant $H(f, L)$ and $\Delta(f, L)=2-H(f, L)$. The higher the fractal dimension, the higher the chaotic aspect of the profile.

\section{Appendix B}

The two-way ANOVA is based on the same statistical principles as the one-way ANOVA except that it involves two independent qualitative variables instead of one. These two independent variables (in this investigation: the initial morphological texture of the coating and the surface state) are called factors and the basic idea is that these factors may affect the dependent variable under consideration. Each factor is characterised by two or more levels and by a degree of freedom equal to the number of levels minus one. As for the one-way ANOVA, the principle of the two-way ANOVA is to evaluate the Null Hypothesis $H_{0}$ except that the treatment turns on each factor considered as independent (treatments of the main effects) and on their interaction (treatment of the interaction effect between the two factors).

From a formal point of view, this statistical method is mathematically based on the model $X_{i j r}=\alpha_{i}+\beta_{j}+\gamma_{i j}+\varepsilon_{i j r}$ where $\alpha_{i}, \beta_{j}, \gamma_{i j}, r(\in\{1, \ldots, n\}), \varepsilon_{i j r}$, respectively, represents the main effect of factor $\mathrm{A}(i \in\{1, \ldots, a\})$ being the indexes of the related groups), the main effect of factor $\mathrm{B}(j \in\{1, \ldots, b\})$ being the indexes of the related groups), the interaction effect between factors $\mathrm{A}$ and $\mathrm{B}$, the number of experiments related to each group and the experimental noise related to the dependent variable $X_{i j r}$. Under these conditions, the Null Hypotheses that have to be evaluated are:

$H_{0}^{\mathrm{A}}: \alpha_{i}=0$ for all $i \in\{1, \ldots, a\}$;

$H_{0}^{\mathrm{B}}: \beta_{j}=0$ for all $j \in\{1, \ldots, b\}$ and $H_{0}^{\mathrm{AB}}: \gamma_{i j}=0$ for all $i$ and $j$.

The ratio of treatment-group variability (called Mean Square Effect and denoted MSEffect) relative to the within-group variability (called Mean Square Error an denoted MSError) is calculated for each treatment effect (Main and interaction effects). This ratio called Treatment Index and denoted $F^{\text {Effect }}$ follows a Fisher-Snedecor probability density function. For each treatment effect, it is used to evaluate the Null Hypothesis which states that the population treatment means under consideration are equal which means the complete absence of treatment effects. In other words, under the null hypothesis, the variance estimated based on within-group variability should be about the same as the variance due to treatment-group variability. As a consequence, when treatment effects are completely absent, the Treatment Index $F^{\text {Effect }}$ should be approximately equal to one and, when they are present, it should be higher than one. The higher the value of the Treatment Index $F^{\text {Effect }}$, the more statistically significant the treatment effect under consideration.

The evaluation of the Treatment Indexes is carried out thanks to the calculations presented in the following table:

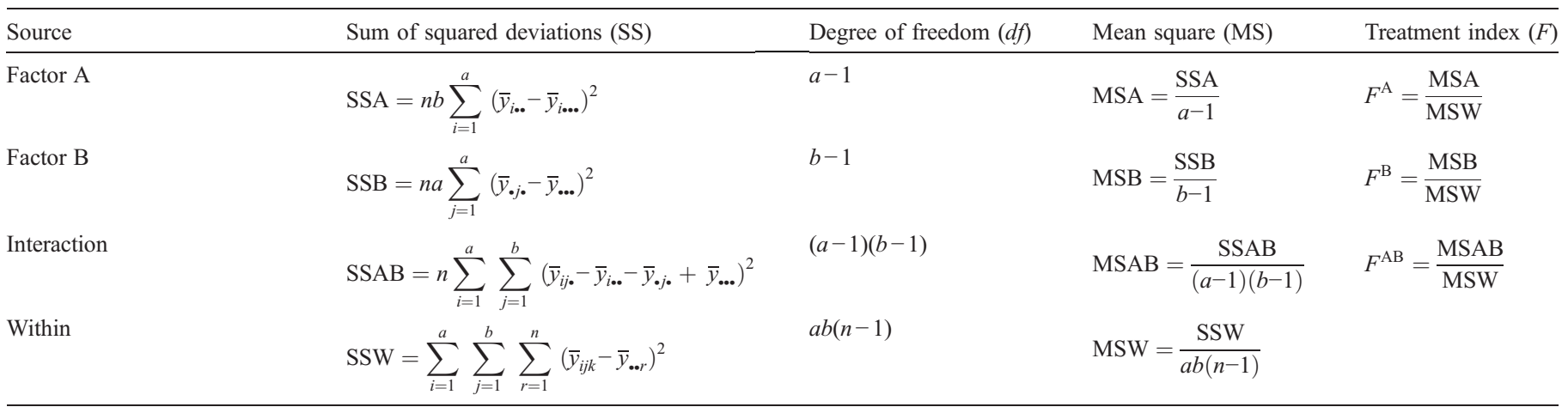




\section{References}

[1] J.M. Soro, L. Lelait, J.C. van Duysen, G. Zacharie, J. von Stebut, Surf. Coat. Technol. 98 (1998) 1490.

[2] S. Amada, K. Imagawa, S. Aoki, Surf. Coat. Technol. 154 (2002) 27.

[3] G. Reisel, R.B. Heimann, Surf. Coat. Technol. 185 (2004) 215.

[4] M. Ahrens, R. Vassen, D. Stöever, Surf. Coat. Technol. 161 (2002) 26.

[5] M. Mellali, P. Fauchais, A. Grimaud, Surf. Coat. Technol. 81 (1996) 275.

[6] J. Takadoum, H. Houmid Bennani, Surf. Coat. Technol. 96 (1997) 272.

[7] S. Amada, T. Hirose, Surf. Coat. Technol. 102 (1998) 132.

[8] K.H. Kim, D.S. Han, S.K. Kim, Surf. Coat. Technol. 163-164 (2003) 605.

[9] S.J. Bull, P.R. Chalker, C. Johnston, V. Moore, Surf. Coat. Technol. 68-69 (1994) 603.

[10] D.P. Liu, G. Benstetter, Y.H. Liu, J.L. Zhang, C.S. Ren, T.C. Ma, Surf. Coat. Technol. 174-175 (2003) 310.

[11] B. Podgornik, S. Hogmark, O. Sandberg, Surf. Coat. Technol. 184 (2004) 338.

[12] K.C. Shimpi, K. Ravindranath, A.K. Jani, D.C. Kothari, C.S. Harindranath, Surf. Coat. Technol. 90 (1997) 115.

[13] T.E. Fletcher, Prog. Org. Coat. 44 (2002) 25.

[14] J.S. Preston, L.F. Gate, Colloids Surf., A Physicochem. Eng. Asp. 252 (2004) 99.

[15] D.J. Whitehouse, Wear 83 (1982) 75.

[16] M. Bigerelle, D. Najjar, A. Iost, J. Mater. Sci. 38 (2003) 2525.
[17] D. Najjar, M. Bigerelle, A. Iost, Wear 254 (2003) 450.

[18] A. Iost, D. Najjar, K. Anselme, M. Bigerelle, Mat. Sci. Forum 462-463 (2003) 3031 .

[19] L. Lin, G.S. Blackman, R.R. Matheson, Prog. Org. Coat. 40 (2000) 85.

[20] L. Lin, G.S. Blackman, R.R. Matheson, Mat. Sci. Eng. A317 (2001) 163.

[21] W. Shen, B. Jiang, S.M. Gasworth, H. Mukamal, Tribol. Int. 34 (2001) 135.

[22] C.D. Diakoumakos, F.N. Jones, Surf. Coat. Technol. 150 (2002) 37.

[23] A. Iost, D. Najjar, R. Hellouin, Surf. Coat. Technol. 165 (2003) 126.

[24] B. Lambotte, 'Les mécanismes de rayure des vernis de finition automobile', PhD, 2001, Ecole Centale de Lyon, France.

[25] Techniques de l'ingénieur A3 785 - 3.

[26] E.J. Abbott, F.A. Firestone, Mech. Eng. (Am. Soc. Mech. Eng.) 59 (1933) 569.

[27] M. Bigerelle, D. Najjar, A. Iost, Rev. Métall. (2002) 467.

[28] M. Bigerelle, A. Iost, C. R. Acad. Sci. Paris 323 (Série II b) (1996) 669.

[29] H. Scheffe, The Analysis of Variance, J. Willey, New York, 1959.

[30] B. Efron, Ann. Stat. 7 (1979) 1.

[31] B. Efron, R.J. Tibshirani, An Introduction to the Bootstrap, Chapman and Hall, 1993.

[32] P. Hall, The Bootstrap and the Edgeworth Expansion, Springer-Verlag, 1992. 